\title{
A FRAMEWORK TO DEVELOP FLAW ACCEPTANCE CRITE RIA FOR STRUCTURAL INTE GRITY ASSESSMENT OF MULTIPURPOSE CANISTERS FOR EXTENDED STORAGE OF USED NUCLEAR FUEL
}

\author{
Poh-Sang Lam \\ Materials Science and Technology \\ Savannah River National Laboratory \\ Aiken, SC 29808, USA \\ ps.lam@srnl.doe.gov \\ Andrew J . Duncan \\ Materials Science and Technology \\ Savannah River National Laboratory \\ Aiken, SC 29808, USA \\ andrew.duncan@srnl.doe.gov
}

\author{
Robert L. Sindelar \\ Materials Science and Technology \\ Savannah River National Laboratory \\ Aiken, SC 29808, USA \\ robert.sindelar@srnl.doe.gov
}

Thad M. Adams

Materials Science and Technology

Savannah River National Laboratory

Aiken, SC 29808, USA

thad.adams@srnl.doe.gov

\section{ABSTRACT}

A multipurpose canister (MPC) made of austenitic stainless steel is loaded with used nuclear fuel assemblies and is part of the transfer cask system to move the fuel from the spent fuel pool to prepare for storage, and is part of the storage cask system for on-site dry storage. This weld-sealed canister is also expected to be part of the transportation package following storage. The canister may be subject to service-induced degradation especially if exposed to aggressive environments during possible very long-term storage period if the permanent repository is yet to be identified and readied. Stress corrosion cracking may be initiated on the canister surface in the welds or in the heat affected zone because the construction of MPC does not require heat treatment for stress relief. An acceptance criteria methodology is being developed for flaw disposition should the crack-like defects be detected by periodic Inservice Inspection. The external loading cases include thermal accident scenarios and cask drop conditions with the contribution from the welding residual stresses. The determination of acceptable flaw size is based on the procedure to evaluate flaw stability provided by A merican Petroleum Institute (API) 579 Fitness-for-Service (Second Edition). The material mechanical and fracture properties for base and weld metals and the stress analysis results are obtained from the open literature such as NUREG-1864. Subcritical crack growth from stress corrosion cracking (SCC), and its impact on inspection intervals and acceptance criteria, is not addressed.

\section{INTRODUCTION}

Nuclear energy systems continue to be a significant and growing component of the worldwide energy portfolio. However, the final disposition of used nuclear fuel (UNF) represents a continued challenge to the long-term viability of nuclear energy. The used fuel are initially stored in storage pools and then transferred to dry cask storage after sufficient time to allow cooling via radioactive decay. The present regulatory basis for dry cask storage is 60 years but longer storage times will likely become necessary as the U.S. Department of Energy (DOE) and the U. S. Nuclear Regulatory Commission (NRC) evaluate repository and reprocessing components under the modified open cycle strategy. In addition, even as the UNF storage times are projected to extend far beyond 60 years, the trend in the commercial power production industry is to push fuel to higher burn-up ( $>45 \mathrm{GWD} / \mathrm{t}$ ), partially because of the shortage of the storage pool capacity. This creates a UNF storage challenge as higher burn-up increases cladding degradation, 
fission product concentrations, and other phenomena that will affect the performance of UN F storage facilities.

Therefore, the nuclear industry is facing a critical issue in the extended storage of sealed stainless steel canisters in Dry Cask Storage Systems at Independent Spent Fuel Storage Installations. The vulnerability to instability crack growth under marine salt and industry deposit contaminants will compromise the safety-credited containment boundary of the storage system such as the multipurpose canisters (M PC).

Flaws may have been initiated in these canisters in the dry storage system due to material degradation resulting from service conditions and environmental attack. The NDE (nondestructive evaluation) or NDT, (non-destructive testing) techniques are being developed to detect service-induced planar and non-planar flaws (e.g., cracking and pitting) in limited-access locations. A consensus approach for inspection that would be expected to follow general ASME Section XI rules, and that would include acceptance standards for flaw disposition, has not been established for this component.

It is proposed to develop a fracture mechanics-based flaw disposition protocol to establish the acceptance criteria for continued service of these canisters in the dry storage system. The first step in protocol development would be the determination of instability crack lengths for flaw postulates at critical canister locations under loading conditions. Instability crack lengths would be estimated based on the fracture toughness of the materials of construction. The service loads may include accident conditions in combination of the residual stress since the canisters may not be stress relieved after welding. The evaluation of flaw stability for the purpose of developing flaw acceptance criteria is outlined in this paper. Subcritical flaw growth, which could occur with SCC, would be also considered in the establishment of intervals under an inservice inspection program. This would include, for example, a more frequent examination of reported flaws. This consideration is outside the scope of this paper.

\section{MPC CONFIG URATIONS}

There are many used nuclear fuel storage and transportation systems in service. The present paper is only intended to propose and outline a flaw disposition methodology for structural integrity assessment of a stainless steel multipurpose canister (MPC). A typical cask system, Holtec International Storage Module, (HI-STORM) [1,2] is considered in the present work, inside which the MPC is inserted. The MPC is a cylindrical shell structure with all components made of austenitic stainless steel [3]. The canister height is $4.8 \mathrm{~m}(15.8 \mathrm{ft})$ and the (outer) diameter is $1.73 \mathrm{~m}(5.7 \mathrm{ft})$. The shell thickness is $1.27 \mathrm{~cm}(0.5 \mathrm{in}$.). The fuel assemblies are loaded vertically into the MPC. With BWR fuel, the canister weight would be 36 metric tons (40 tons). The cylindrical shell is constructed with a circumferential (girth) weld in the mid-height and four axial seam welds. The upper and lower axial welds are offset slightly along the circumferential weld. The shell is welded to a bottom plate with a thickness of $6.35 \mathrm{~cm}$ (2.5 in.) [1]. These are full penetration submerged arc (SA) welds and are subject to post-weld nondestructive inspections but are not heat treated for (residual) stress relief. The flaw acceptance criteria will be developed in these critical locations. Figure 1 (reproduced from [1]) shows the weld configurations.

After the used fuel assemblies are loaded into the canister, a lid is welded to the top of the cylindrical shell. These welds were not considered in the MPC failure assessment [1] because 1 ) the tungsten inert gas (TIG) welds are tougher than those SA welds in the body of the shell and baseplate; 2 ) the multiple welds in the lid provide redundant safety features, and 3 ) the lower stresses are expected in the lid.

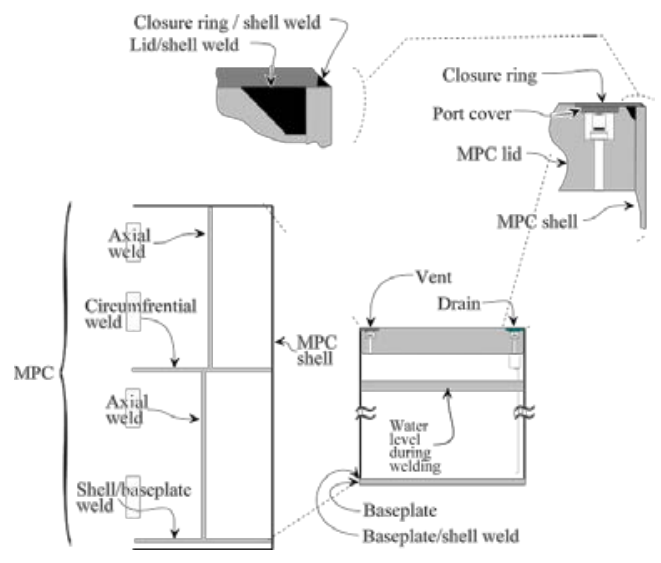
Figure 1 Welds on a Multipurpose Canister
(Reproduced from NUREG-1864, [1], Fig. 16)

\section{FRACTURE METHODOLOGIES}

Two general approaches in developing flaw acceptance criteria are described below. One is based on the critical J integral value (or equivalently stress intensity factor, $K$ ) and the other is the failure assessment diagram (FAD).

\section{J -Integral and Tearing Modulus ( -T Approach)}

The fracture toughness (e.g., $K_{I C}$ or $J_{I C}$ in Mode I fracture) and J-resistance curves (J -R) are typically determined by testing methods recommended by ASTM standards. The $J-R$ curve represents the material resistance of ductile crack growth and the test data can be fit with a power law expression (ASTM E1820-13 Standard Test Method for $M$ easurement of $F$ racture Toughness):

$J=C(\Delta a)^{m}$

where $\mathrm{C}$ and $\mathrm{m}$ are curve fitting parameters, and $\Delta \mathrm{a}$ is the crack growth increment. 
The tearing stability of the material is characterized by the tearing modulus $(T)$ :

$T=\frac{E}{\sigma_{0}^{2}} \frac{d J}{d a}$

where $\sigma_{0}$ is the $0.2 \%$ yield stress and $\mathrm{E}$ is the Young's modulus. Note that the tearing modulus is proportional to the slope of the J-R curve (dJ/da) as the crack extends to length $a$. Instability flaw lengths are evaluated based on the loading conditions of the structural component and are determined by an elastic-plastic J-integral or J-T analysis. The crack growth $\left(J \geq J_{I C}\right)$ is stable if $T<T_{R}$, where $T_{R}$ is the tearing modulus of the material. The intersection point of the "applied" J-T curve (obtained by analysis due to external loading) and the "material" J -T curve (obtained by fracture testing as a material property) will define the stable crack growth limit. The J-estimation scheme was developed in General Electric Company (GE) for Electric Power Research Institute (EPRI) by K umar et. al. in early 1980 s [4,5] based on Hutchinson-Rice-Rosengren (HRR) singularity solution for power law materials. All the angular functions needed to evaluate the values of the $\mathrm{J}$-integral up to $R / t=20$ (where $R$ is the pipe radius and $t$ is the wall thickness) have been tabulated in their reports. Subsequently, in $1993 \mathrm{Lam} \mathrm{[6]} \mathrm{and} \mathrm{Ji} \mathrm{et} \mathrm{al.}$ [7] extended the $r / t$ range to 40 as part of the Structural Integrity Program at the U. S. Department of Energy Savannah River Site (SRS) for the aging national defense production reactor systems. The J-T methodology is based on fracture mechanics analysis.

\section{Failure Assessment Diagrams (FAD Approach)}

The failure assessment diagram (FAD) is a crack growth resistance curve in terms of $L_{r}$ (abscissa) and $K_{r}$ (ordinate), where the stress ratio $L_{r}$ is traditionally defined as the ratio of the applied load $(P)$ to a reference load $\left(P_{0}\right)$; and $K_{r}$ and $I_{r}$ are the ratios of elastic force to the resisting force:

$L_{r}=P / P_{0}$

$\mathrm{K}_{\mathrm{r}}=\mathrm{K}(\mathrm{a}, \mathrm{P}) / \mathrm{K}_{\mathrm{R}}(\Delta \mathrm{a})$

$J_{r}=J^{e}(a, P) / J_{R}(\Delta a)$

where $\mathrm{K}$ is the stress intensity factor at the tip of a crack due to the applied load, and $K_{R}$ is related to $J_{R}$ as $K_{R}^{2}(\Delta a)=E^{\prime}$ $J_{R}(\Delta a)$ and is the fracture toughness of the material (e.g., $K_{I C}$ or $\left.J_{\text {Ic }}\right)$. This relation is strictly valid for linear elastic deformation or under small scale yielding conditions. The elastic portion of $\mathrm{J}$-integral, $\mathrm{J}{ }^{\mathrm{e}}$, is the elastic crack driving force and can be written as $\mathrm{J}^{\mathrm{e}}=\mathrm{K}^{2} / \mathrm{E}^{\prime}$. In these expressions, $\mathrm{E}^{\prime}=\mathrm{E}$ for plane stress, $\mathrm{E}^{\prime}=\mathrm{E} /\left(1-v^{2}\right)$ for plane strain, and $v$ is the Poisson's ratio. Under these circumstances, the nondimensional $K_{r}$ and $\mathrm{J} r$ are related by

$$
K_{r}^{2}(a, P, \Delta a)=J_{r}(a, P, \Delta a)
$$

When the assessment point is below this curve, the crack is considered as stable. The original FAD methodology was developed in 1986 by Milne et al. [8] as the CEGB (Central Electric Generating Board, U.K.) R6 procedure (Assessment of the Integrity of Structures Containing Defects). The FAD also has sound technical basis, but has been considered as a codified approach.

\section{DEVELOPMENT OF FLAW ACCEPTANCE CRITERIA FOR MULTIPURPOSE CANISTERS (MPC)}

Based on the safety analysis reports [1,2], the potential crack initiation or stress corrosion sites are identified in the weld regions because the canister is not heat treated for welding residual stress relief. In this work, two off-normal conditions are considered: 1 ) thermal accidents and 2) canister drop events.

A general procedure in developing flaw acceptance criteria is to calculate (or estimate) the instability crack length (or depth) in the critical location of the structure with respect to a set of external loads. Therefore, a structural stress analysis is usually performed first to identify the locations where high stress (or high strain) may occur as a result of externally applied loads (such as thermal mismatch and mechanical loading) and to quantify the magnitude of the local stress. Then a postulated crack or an existing flaw is assumed under the influence of the calculated stress as the background stress in a simplified configuration. The "applied" stress intensity factors $\left(K_{1}\right)$ or the values of the J integral $\left(J_{1}\right)$ will be calculated with respect to this given background stress by gradually increasing the flaw size until the $K_{1}$ or $J_{1}$ reaches the material fracture toughness ( $K_{I C}$ or $\left.J_{I C}\right)$, at which point the corresponding crack size is defined as the instability crack length or depth. Of course, the most accurate estimation would be to embed the flaw in the full structural model and directly calculate the value of $\mathrm{K}$ or $\mathrm{J}$. However, such practice involves extremely labor intensive modeling and finite element meshing and CPU intensive computations, therefore, it is rarely adopted.

As discussed earlier, both fracture methodologies, namely, the J-T approach and FAD approach, require the estimation of $\mathrm{K}$ or J due to the applied force. B ecause the R/t ratio of the M PC shell is $68((1.73$ meters $\div 2) / 1.27 \mathrm{~cm})$, it has exceeded the range of applicability of the GE solution (up to $R / t=20$ ) $[4,5]$ and the SRS extended solution (up to $R / t=40$ ) $[6,7]$. Therefore, the J-integral is not readily estimated by the EPRI scheme. As a result, it is proposed that the present work on developing flaw acceptance criteria will be based on the FAD procedure, which is endorsed jointly by the A merican Petroleum Institute (API) and the A merican Society 
of M echanical Engineers (ASME) in the document API 5791/ASME FFS-1: Fitness-for-Service, which is also known as API 579 Second Edition 2007 [9].

It should be noted that J-T and FAD are both acceptable by international consensus codes such as API 579. Furthermore, the results of predicting instability crack length (or depth in the case of part-through wall cracks) can be very similar regardless J-T or FAD is used. This has been demonstrated by Lam [10] and by Lam and Sindelar [11] in the case of SRS high level nuclear waste tanks.

\section{Stress Analysis}

The structural analyses have been carried out for various cask designs each with an MPC inserted as an integrated package, for example, the Safety Analysis of HI-STORM system [2]. However, not all safety analysis documentations along with the supporting finite element analyses are available in the open literature. M ost of the stresses that are needed for developing flaw acceptance criteria in this work are extracted from a probabilistic risk assessment report, NUREG-1864 [1], which references some stress analysis results reported in $\mathrm{HI}$ 2002444 [2].

\section{Material Properties}

The design temperature for the MPC shell is $237{ }^{\circ} \mathrm{C}$ $\left(459^{\circ} \mathrm{F}\right)$ [1, Table A.1]. The material of construction is stainless steel Type 304, although 304L N, 316, and 316L might be used. Because the yield and ultimate strengths of Type 304 represent the lower bound properties of these stainless steels, the material properties of Type 304 were used in stress analysis and the risk assessments [1]. The Table A.2 of NUREG-1864 [1] for the mechanical properties of Type 304 is reproduced below:

Table 1 Material Properties of $\mathbf{3 0 4}$ Stainless Steel

\begin{tabular}{|c|c|c|c|c|c|c|}
\hline$M$ aterial & $\begin{array}{l}\text { Temp. } \\
{ }^{\circ} \mathrm{C} \\
\left({ }^{\circ} \mathrm{F}\right)\end{array}$ & $\begin{array}{l}\text { Young's } \\
\text { M odulus } \\
\text { GPa } \\
\text { (psi) }\end{array}$ & $\begin{array}{l}\text { Y ield } \\
\text { Stress } \\
\text { M Pa } \\
\text { (psi) }\end{array}$ & $\begin{array}{l}\text { Tangent } \\
\text { M odulus } \\
\text { M Pa } \\
\text { (psi) }\end{array}$ & $\begin{array}{l}\text { Eng. } \\
\text { Strain } \\
\text { at } \\
\text { Failure } \\
(\mathrm{m} / \mathrm{m})\end{array}$ & $\begin{array}{l}\text { M in. } \\
\text { True } \\
\text { Strain } \\
\text { at } \\
\text { Failure } \\
(\mathrm{m} / \mathrm{m})\end{array}$ \\
\hline \multirow{4}{*}{$\begin{array}{l}\text { Stainless } \\
\text { Steel } \\
\text { Type } \\
304\end{array}$} & $\begin{array}{l}393 \\
(740)\end{array}$ & $\begin{array}{l}162 \\
(2.35 \mathrm{E} 7)\end{array}$ & $\begin{array}{l}161 \\
(23386)\end{array}$ & $\begin{array}{l}710 \\
(1.03 E 5)\end{array}$ & 0.377 & 0.92 \\
\hline & $\begin{array}{l}237 \\
(459)\end{array}$ & $\begin{array}{l}180 \\
(2.61 \mathrm{E} 7)\end{array}$ & $\begin{array}{l}264 \\
(38344)\end{array}$ & $\begin{array}{l}403 \\
(5.85 \mathrm{E} 4)\end{array}$ & 0.456 & 0.92 \\
\hline & $\begin{array}{l}162 \\
(323)\end{array}$ & $\begin{array}{l}185 \\
(2.69 \mathrm{E} 7)\end{array}$ & $\begin{array}{l}308 \\
(44719)\end{array}$ & $\begin{array}{l}317 \\
(4.60 \mathrm{E} 4)\end{array}$ & 0.48 & 0.92 \\
\hline & $\begin{array}{l}106 \\
(223)\end{array}$ & $\begin{array}{l}190 \\
(2.75 \mathrm{E} 7)\end{array}$ & $\begin{array}{l}352 \\
(51012)\end{array}$ & $\begin{array}{l}278 \\
(4.03 E 4)\end{array}$ & 0.498 & 0.92 \\
\hline
\end{tabular}

From NURE G-1864 [1], the weld metal for M PC shell is typically Type 308. The A SM E code requires that the weld strength is equal or greater than the base metal. The test data reported by Stoner et al. [12] obtained under the Reactor $M$ aterials Program for SRS production reactor process water piping system were referenced by NUREG-1864 and were used to justified that no distinction was made between the base and weld metals in the stress analysis and in the probabilistic risk assessment $[1,2]$. The Table B.1 in NUREG-1864 [1] lists that the $M$ ean Reduction in A rea (RA) for Type 304 base metal, Type 308 weld metal, and the heat-affected zone (HAZ) are, respectively, $72 \%, 61 \%$, and $71 \%$, from SRS legacy data report [12].

No significant changes to the mechanical properties of the stainless steel materials are expected due to thermal and radiation exposure at bounding conditions estimated for very long term storage periods [13].

\section{Stress from Thermal Loads}

One of the MPC stresses considered is from thermal loads [1, Appendix B] due to two thermal accident scenarios: 1) the storage cask is subject to external fire and 2) the storage cask has vent blockage. These accidents lead to internal pressure increase and the equations to evaluate the stresses are basically the standard textbook formulae: The axial stress is $\mathrm{pr} /(2 \mathrm{t})$ and the hoop stress is $p r / t$, where $p$ is the internal pressure of the $M P C$ and is a function of temperature. However, the highest stress was found at the shell-to-baseplate (bottom plate) connection due to the existence of membrane bending stress. Figure 2 is a reproduction of Fig. B.2 in NUREG-1864 [1]. $N$ ote that the accident scenario started from the steady state temperature under normal operation, that is, $0.565 \mathrm{M} \mathrm{Pa}(82$ psi). The hoop and axial stressed are useful for developing flaw acceptance criteria in the M PC axial and circumferential welds and the highest stress with bending component can be used for acceptance criteria at the junction between the M PC shell and the bottom plate.

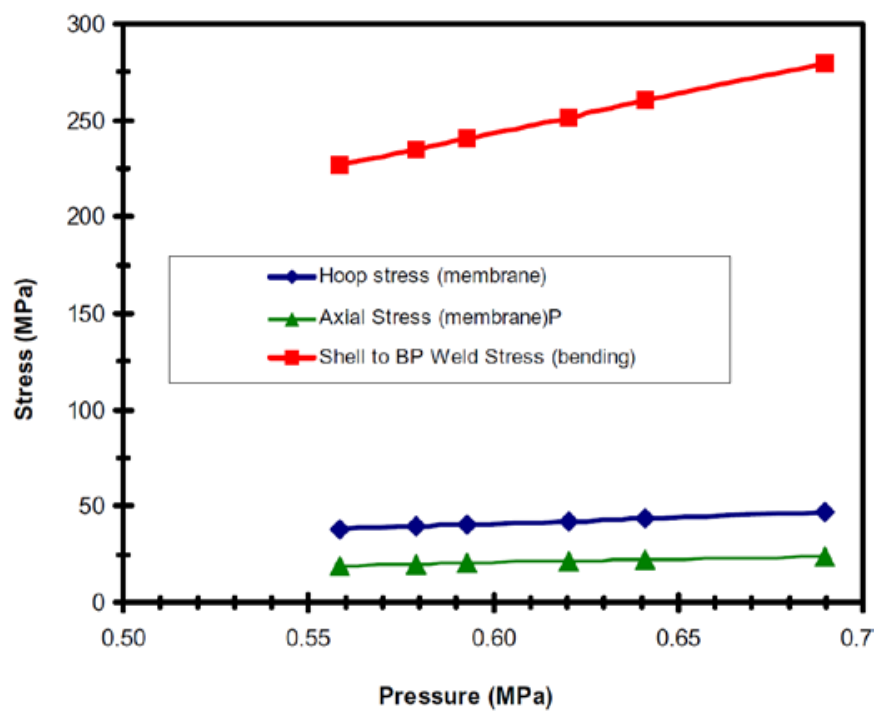

Figure 2 Maximum Stresses in MPC Thermal
Accidents (Reproduced from
NUREG-1864 [1], Fig. B.2) 
Stress from MPC Drop Events

The stresses for the cask drop events were not reported in NUREG-1864 [1]. Instead, the maximum effective plastic strains (EPS) calculated from HI-2002444 [2] were used in probabilistic risk assessment for weld failure. The SRS legacy data [12] for base metal Type 304 and weld metal Type 308 were referenced. The maximum EPS is found to be 0.256 in a 100 -foot drop of the cask on concrete floor. The location of the maximum EPS is on the inside surface of the M PC shell beneath the basket support. Table 2 is reproduced from Table B.3 in NUREG-1864 [1] and the maximum EPS calculated for all cask drop events are tabulated. B ecause the deformation in a structure is usually under multiaxial state, NUREG-1864 [1] used a triaxiality factor to adjust the finite element calculated values, which are also shown in Table 2.

\section{Table 2 Maximum Effective Plastic Strains (EPS)} from Cask Drops (NUREG-1864 [1] Table B.3)

\begin{tabular}{|l|c|c|c|}
\hline $\begin{array}{c}\text { Drop Height } \\
\mathrm{m}(\mathrm{ft})\end{array}$ & $\begin{array}{c}\text { M ax. EPS } \\
(\mathrm{m} / \mathrm{m})\end{array}$ & $\begin{array}{l}\text { M ax. EPS } \\
\text { adjusted for } \\
\text { Triaxiality } \\
(\mathrm{m} / \mathrm{m})\end{array}$ & $\begin{array}{l}\text { Probability } \\
\text { of Weld } \\
\text { Crack } \\
\text { Initiation }\end{array}$ \\
\hline $1.524(5)$ & 0.024 & 0.048 & $<1.0 \times 10^{-6}$ \\
\hline $12.192(40)$ & 0.195 & 0.213 & 0.00036 \\
\hline $21.336(70)$ & 0.24 & 0.285 & 0.0026 \\
\hline $30.48(100)$ & 0.256 & 0.385 & 0.0196 \\
\hline
\end{tabular}

The finite element calculated stresses for the cask drop events may have been included in Cask Safety Analysis Reports such as HI-2002444 [2], but the complete versions are not always available because of proprietary concerns. For the current work it is proposed to obtain the corresponding stress with respect to the EPS in Table 2 by using the appropriate uniaxial stress-strain curve or data such as 1) the information from Table 1, which suggests bilinear stress-strain relationship or 2) from SRS legacy data [12]. These critical stresses will allow the "applied" stress intensity factors K (and/or $J_{1}$ ) be calculated for the MPC shell that contains a crack. The calculation procedure is described in API 579 [9] (also see later sections for details). Along with the fracture toughness $\left(K_{I C}\right)$ of the materials, which can be found in open literature or from the SRS Reactor M aterials Program [12], the parameter $\mathrm{K}_{\mathrm{r}}$ in the FAD approach (ordinate of the assessment point) is then readily to be calculated.

\section{Weld Residual Stress}

The axial and circumferential welds and the shell-tobaseplate weld in MPC are not stress relieved. These residual stresses may play an important role on crack initiation due possibly to stress corrosion and will influence the subsequent crack growth. Therefore, the total "applied" stress intensity factor or the J-integral must include the contribution from residual stress. Without simulating the welding process with the prerequisite that all welding parameters must be welldefined and known, or without actual measurement being performed on the welded components, it is challenging to estimate the true value of the residual stress. Therefore, it is proposed in this work that A PI 569 A nnex E [9] be utilized for estimating the code-acceptable residual stresses for MPC structural integrity assessment. As noted by API 579 Section E.2.4 [9, Annex E), the evaluation procedure makes no distinctions in the materials of construction, but it is recommended for ferritic and stainless steel weldments. Therefore, the equations in API 569 A nnex E [9] are suitable for the M PC welds. Note that those suggested equations are weld joint geometry-dependent, such as double $\mathrm{V}$ or single $\mathrm{V}$ configurations.

\section{Fitness-for-Service Assessment}

The API 579 [9, Part 9] suggests that Level 3 A ssessment provide the best estimate of the structural integrity of a component with a crack-like flaw. It is also required if subcritical crack growth may be expected during future operation. Therefore, Level 3 A ssessment is appropriate for assessing the structural performance of MPC. A "materialspecific" FAD may be constructed based on the tensile properties of the material. The definitions of the FAD parameters are shown in the footnotes under Fig. 9.20 in A PI 579 [9]. A typical FAD is shown in Fig. 3 (reproduced from API 579). The flaw size that leads to the assessment point exactly fallen on the failure assessment curve will define the instability crack size for a given load. Note that there are 5 methods permitted in Level 3 A ssessment, where the materialspecific failure assessment curves are defined by different equations. The API 579 Level 3 Assessment has been applied previously in developing the flaw acceptance criteria for SRS high level waste tanks by Lam [10] and by Lam and Sindelar [11].

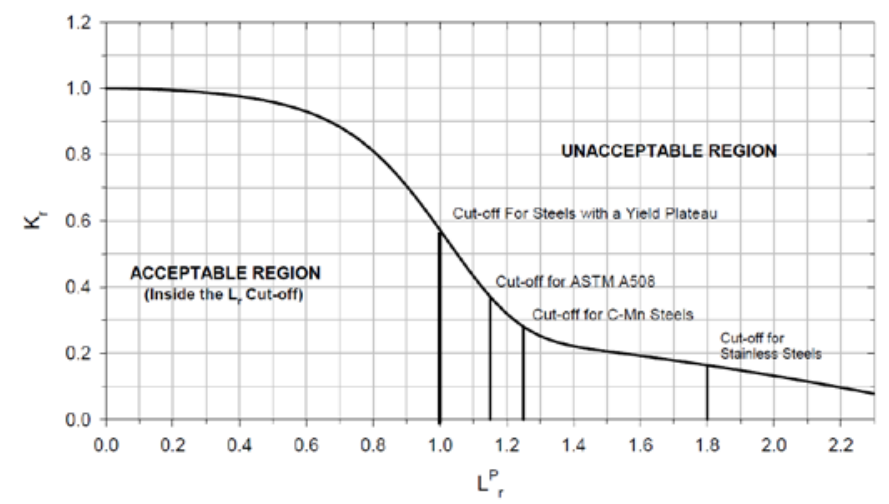

Figure 3 Typical Failure Assessment Diagram (reproduced from API 579 [9] Fig. 9.20)

The next two sections are used to outline how the assessment point, with coordinates $\left(\mathrm{K}_{r}, \mathrm{~L}_{\mathrm{r}}\right)$, is estimated by API 579 procedure [9]. For a given background stress (from 
stress analysis), the calculation will start from an initial crack size (e.g., the detection limit or threshold of NDE or NDT if the component contains no existing flaws), the coordinates of the assessment point are re-evaluated as the flaw is postulated to grow incrementally. This series of assessment points forms a locus in the FAD. The intersection point of this locus and the failure assessment curve will define the instability crack size.

\section{Stress Intensity F actor Solutions}

As mentioned earlier, the $\mathrm{R} / \mathrm{t}$ ratio of the MPC shell exceeds the range of validity of the traditional EPRI solutions for $K$ or J [4-7], other similar estimation schemes are needed for a quick assessment without resorting to the time consuming finite element analysis. It was found that the API 579 Second Edition [9] has provided the stress intensity factor solutions for a full range of $\mathrm{R} / \mathrm{t}$ (i.e., 0 to $\infty$ ), so the ordinate of the assessment point $\left(K_{r}=K / K_{c}\right)$ can be easily calculated for a specific crack size. In addition, API 579 provides the lessknown solutions for external cracks, which is most likely the case for M PC when it is exposed to the harsh environments.

The stress intensity factor solutions for both Iongitudinal and circumferential cracks are available from API 579 A nnex C Section 5 [9]. The functions and parameters needed for the calculation of an external crack are tabulated in Table C.15 of API 579 [9].

\section{Reference Stress (Limit Load) Solutions}

The parameter $L_{r}$ (defined earlier in this paper and in [8]) is alternatively defined in A PI 579 A nnex D [9] as the "load ratio based on primary stress.", and is denoted by $L_{r}{ }^{p}=\sigma_{\text {ref }} / \sigma_{y s}$, where $\sigma_{\text {ref }}$ is a reference stress solution [9] and $\sigma_{\mathrm{ys}}$ is the yield stress of the material. The value of $L_{r}$ (or $L_{r}{ }^{p}$ in API 579) is the abscissa of an assessment point for a specific flaw size on the FAD. The API 579 Annex D Section 5 [9] provides reference stress solutions for both longitudinal and circumferential cracks.

\section{SUMMARY}

This paper outlines the framework of estimating the instability flaw size and developing the flaw acceptance criteria for MPC, in particular, under thermal accident scenarios and cask drop events. The complete versions of the stress analysis report are unavailable in open literature, therefore, the stresses needed for structural integrity assessment is proposed to be extracted from the uniaxial stress-strain relationship based on the equivalent plastic strains (EPS) reported in NUREG-1864 [1]. B ecause the R/t ratio of the MPC shell exceeds the valid range of EPRI estimation solutions for $K$ and $J$, the FAD approach in API 579 Part 9 with Level 3 Assessment [9] should be used to develop the flaw acceptance criteria. The instability flaw size is determined by the intersection point of the assessment locus and the failure assessment curve. The flaw acceptance criteria for MPC shell are based on the calculated instability flaw size.

\section{ACKNOWLEDGEMENT}

This work was supported by the Laboratory-Directed Research and Development (LDRD) program at the Savannah River National Laboratory and by the Savannah River Nuclear Solutions, LLC under Contract No. DE-A C09-08SR 22470 with the U.S. Department of Energy.

\section{REFERENCES}

[1] Bjorkman, G., Chuang, T.-J., Einziger, R., Malik, S, Malliakos, A., Mitchell, J, Navarro, C., Ryder, R., Shaukat, S., Ulses, A., and Zigh, G., 2007, "A Pilot Probabilistic Risk Assessment of a Dry Cask Storage System at a Nuclear Power Plant", NUREG-1864, U.S. Nuclear Regulatory Commission Washington, DC.

[2] HOLTEC International, September 6, 2002, "HOLTEC International Final Safety Analysis Report for the HISTORM Cask System," HI-2002444, Marlton, New Jersey

[3]http://www.hol tecinternational.com/productsandservices/w asteandfuelmanagement/multi-purpose-canisters/

[4] Kumar, V., German, M.D., and Shih, C.F., 1981, Engineering Approach for Elastic-Plastic Fracture Analysis, EPRI NP-1931, General Electric Company, Schenectady, N ew Y ork.

[5] Kumar, V., German, M.D., Wilkening, W.W., A ndrews, W.R., deL orenzi, H.G., and Mowbray, D.F., 1984, Advances in Elastic-Plastic Fracture Analysis, EPRI NP3607, General Electric Company, Schenectady, N ew Y ork.

[6] Lam, P.S., 1993, "Elastic-Plastic J-integral Estimation $M$ ethod and Crack Stability A nalysis for Large Diameter Piping under Bending," W SRC-TR-93-252, Westinghouse Savannah River Company, Aiken, South Carolina.

[7] Ji, W., Chao, Y.J., Sutton, M .A., L am, P.S., and M ertz, G.E., 1993, "J-integral of Circumferential Crack in Large Diameter Pipes," the Second ASME/JSME Nuclear Engineering J oint Conference, San Francisco, California, Vol. 2, pp. 139-149.

[8] Milne, I, Ainsworth, R.A., Dowling, A.R., and Stewart, A.T., 1986, "Assessment of the Integrity of Structures Containing Defects," Central Electricity Generating Board Report R/H/R6-Rev. 3, May 1986; Also in International J ournal of Pressure Vessel \& Piping, Vol. 32, pp. 3-104, 1988.

[9] API 579-1/ASM E FFS-1, 2007, Fitness-F or-Service (API 579 Second Edition), American Petroleum Institute, Washington, DC.

[10] Lam, P.S., 2000, “Comparison of F racture M ethodologies for Flaw Stability A nalysis for High Level Waste Storage 
Tanks (U)," WSRC-TR-2000-00478, Westinghouse Savannah River Company, A iken, South Carolina.

[11] Lam, P.S., and Sindelar, R.L., 2004, "Comparison of Fracture Methodologies for Flaw Stability Analysis of Storage Tanks," in Fracture Methodologies and Manufacturing, Processes, Proceedings of ASME Pressure Vessels and Piping Conference, San Diego, California, PV P-Vol. 474, pp. 91-103.

[12] Stoner, K.J., Sindelar, R.L, and Caskey, G. R., A pril 1991, "Reactor M aterials Program: Baseline Material Property Handbook - Mechanical Properties of 1950s Vintage Stainless Steel Weldment Components," WSRC-TR-9110, Westinghouse Savannah River Company, Aiken, South Carolina.

[13] Sindelar, R.L., Duncan, A.J., Dupont, M.E., Lam, P.-S., L outhan, J r., M .R., and Skidmore, T.E., 2011, "M aterials Aging Issues and Aging $M$ anagement for Extended Storage and Transportation of Spent Nuclear Fuel", NUREG/CR-7116, U.S. Nuclear Regulatory Commission Washington, DC. 